\title{
Vertical and Horizontal Aerosol Scattering Fields over Bellows Beach, Oahu, during the SEAS Experiment*
}

\author{
J. N. Porter, B. R. Lienert, S. K. Sharma, E. Lau, and K. Horton \\ School of Ocean and Earth Science and Technology, Hawaii Institute of Geophysics and Planetology, \\ University of Hawaii at Manoa, Honolulu, Hawaii
}

(Manuscript received 16 July 2002, in final form 18 October 2002)

ABSTRACT

\begin{abstract}
Scanning lidar measurements were carried out during the Shoreline Environment Aerosol Study (SEAS) experiment (19-30 April 2000) to characterize the aerosol scattering fields in the coastal marine boundary layer at Bellows Beach on the southeast side of Oahu, Hawaii. The sea salt was found to be well mixed throughout the mixed layer, although the depth of the trade wind mixed layer was found to vary significantly over short timescales. As expected, the frequency distribution of aerosol scatter had a lognormal distribution, with the exception of regions downwind of breaking waves, where the frequency distribution was bimodal. A spatial statistical study revealed that the island-blocking effects cause low-level clouds to develop as they approach the island, with enhanced drizzle near the coastline reaching all the way to the surface. The spray from waves breaking on an outer reef was found to be intermittent and contained to heights of $20 \mathrm{~m}$ (on average) for the average wind speed of $7 \mathrm{~m} \mathrm{~s}^{-1}$. Sea-salt concentrations and fluxes from the breaking waves were estimated from the lidar measurements and found to be within the range of values reported by other investigators.
\end{abstract}

\section{Introduction}

Small-scale aerosol variability in the coastal marine boundary layer can have significant effects on atmospheric visibility and extinction of light. For instance, under calm dry conditions (few clouds) one can clearly see Molokai and Maui (60 and $100 \mathrm{~km}$ away) from Oahu, Hawaii, but under windy conditions with large spray, even the Molokai outline is not discernible. Understanding and modeling these aerosol fields is of interest for imaging, laser ranging, and optical communication systems. The U.S. Navy has interest in the surfzone-generated aerosols as these could adversely impact the naval operation in the littoral (coastal) region (Richter and Hughes 1991; Jensen et al. 2001). Although the causes of inhomogeneity in marine aerosol optical fields are generally understood, many specific details remain poorly characterized and modeled. Characterizing the magnitude of the different processes responsible for optical extinction in the coastal marine boundary layer is necessary in order to develop realistic models to describe these processes (Vignati et al. 2001).

Different spatial- and temporal-scale processes affect

* School of Ocean and Earth Science and Technology Contribution Number 6045.

Corresponding author address: Dr. J. N. Porter, University of Hawaii at Manoa, 2525 Correa Road, Honolulu, HI 96822.

E-mail: johnport@hawaii.edu optical extinction in the coastal marine boundary layer. Synoptic-scale processes $(\sim 1000 \mathrm{~km})$ such as largescale wind fields, upper-level divergence, and airmass modification affect background salt spray concentrations (Woodcock 1953), atmospheric stability (Albrecht 1984), and vertical mixing in the boundary layer (Stull 1988). Cloud processes, which occur at micro- to mesoscale dimensions $(1-10 \mathrm{~km})$, modulate the background drizzle and aerosol extinction fields in the coastal marine boundary layer (Takahashi 1976; Albrecht 1989). Mountain or island blocking affects the aerosol extinction fields at intermediate scales. Finally, smallscale $(10-100 \mathrm{~m})$ processes such as breaking waves and coastal topography play an important role in the smallscale aerosol concentrations near the coastline.

Scanning lidar measurements can provide detailed spatial maps of aerosol scattering fields in the coastal marine boundary layer in near-real time (Hooper and Martin 1999). From 1998 to 2002, scanning lidar measurements have been carried out on Oahu-initially at Makai Pier and later at Bellows Beach (Bellows Air Force Station) on the windward side of Oahu (Sharma et al. 1998, 2001; Lienert et al. 1999). The Bellows Beach site $\left(21^{\circ} 21^{\prime} \mathrm{N}, 157^{\circ} 42^{\prime} \mathrm{W}\right)$ has a 20 -m tower that is often used for atmospheric sampling of clean marine aerosol. Figure 1 shows the location of the beach, the tower relative to the lidar site, and the reef area 1.5-2 $\mathrm{km}$ offshore. The predominant winds at Bellows Beach are onshore due to the trade winds over the central North 


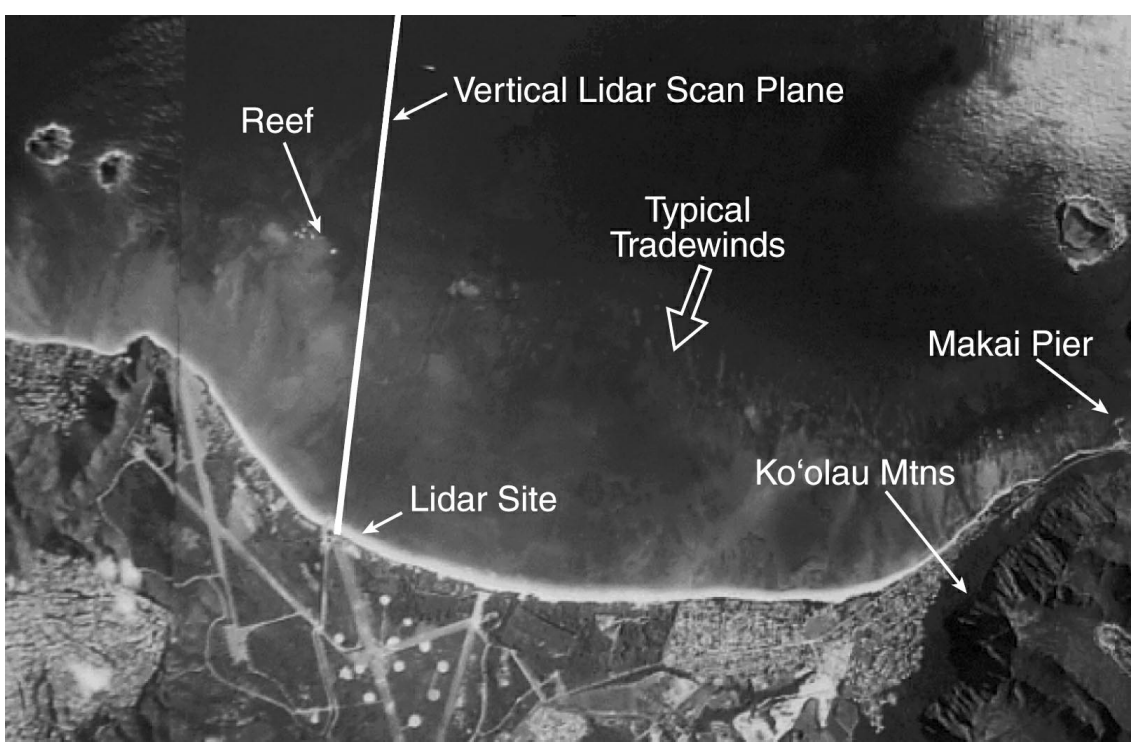

FIG. 1. Image of Bellows Beach on the southeast (windward) side of Oahu. The direction of the typical vertical lidar scan is into the trade wind, as shown. The area of shallowest reef (where breaking waves typically occur) is also indicated.

Pacific (Sadler et al. 1987). The main source of aerosols at Bellows Beach is from waves breaking on the outer reefs (1.5-2 miles out), from waves breaking near the shore (less than $15 \mathrm{~m}$ from our lidar), and from salt spray generated from open-ocean conditions. Although long-range transport of anthrogenic pollution is possible, it typically is not the dominant cause of aerosol extinction in the boundary layer near Oahu.

During 19-30 April 2000, a dedicated experiment, the Shoreline Environment Aerosol Study (SEAS), was carried out using a suite of in situ and lidar aerosol measurements to better characterize the aerosol optical properties at a coastal site (Bellows Beach). The overall experiment and the various instruments involved in the

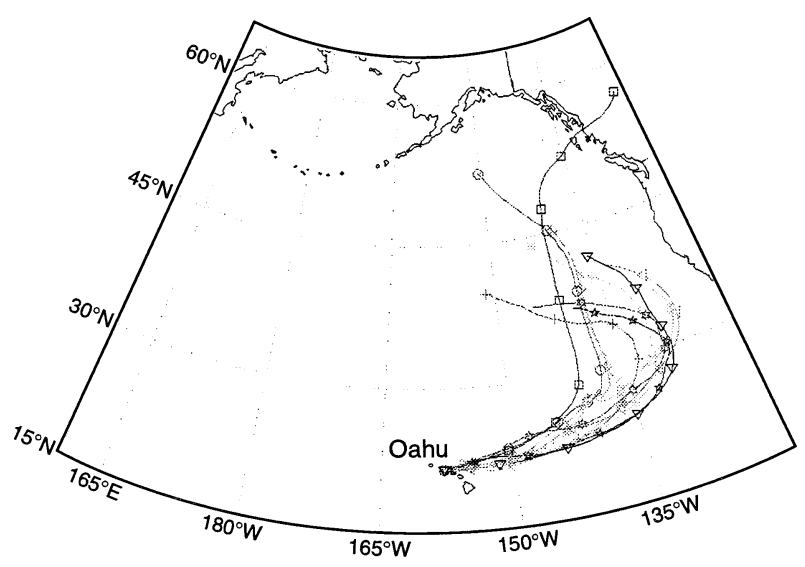

FIG. 2. Seven-day backward trajectories for low-level air arriving at Oahu during the SEAS experiment. Backward trajectories are based on the National Oceanic and Atmospheric Administration (NOAA) Air Resources Laboratory Hybrid Single Particle Lagrangian Trajectory (HY-SPLIT) model.
SEAS experiment are described by Clarke and Kapustin (2003). The meteorological conditions during the SEAS experiment were typical trade wind conditions with 7day back trajectories showing that the source of the air was over the northeast Pacific (Fig. 2). Back trajectories of more than 10 days (Clarke et al. 2003) showed that after 19 April the concentration of the accumulation mode increased due to long-range transport from Asia. Nephelometer measurements (Masonis et al. 2003) showed that this increase in the accumulation-mode aerosol was small, and the aerosol extinction at low levels was still dominated by large aerosols, as evident in aerosol phase function measurements (Lienert et al. 2003).

Our lidar system consists of a coaxial design employing a $30-\mathrm{cm}$ Schmidt-Cassegrain telescope directly coupled to an EMI-9863 photomultiplier tube (PMT). The PMT output is digitized at $60 \mathrm{MHz}(\sim 2.5 \mathrm{~m}$ resolution) with a 12-bit Gage digitizer. During the SEAS experiment a $50-\mathrm{Hz} \mathrm{Nd}$ :YAG laser $(50 \mathrm{~mJ}$ per pulse, at $532 \mathrm{~nm}$ ) was used. The laser beam diameter is expanded to $4 \mathrm{~cm}$. The direction of the lidar is controlled by two motorized scanning mirrors (DFM scanner) for azimuth and zenith motion. A fast diode is used to measure the laser pulse energy and correct for pulse-to-pulse energy variations. Further details of system and software are given in Sharma et al. $(1998,2001)$ and Lienert et al. (1999).

\section{Deriving aerosol scatter measurements from lidar}

The lidar equation (Reagan 1995; Porter et al. 2000) can be written as 


$$
n(r)=\frac{C \beta(r) T(r)^{2}}{r^{2}}
$$

where $n(r)$ is the number of photons from distance $r, C$ is the lidar calibration, $\beta(r)$ is the backscattering coefficient $\left(\mathrm{m}^{-1} \mathrm{sr}^{-1}\right)$ at range $r$, and $T(r)^{2}$ is the two-way transmission given by $T(r)^{2}=\exp \left[-2 \int \sigma_{e}(r) d r\right]$, where $\sigma_{e}(r)$ is the extinction coefficient $\left(\mathrm{m}^{-1}\right)$ at range $r$. The backscattering coefficient is given by $\beta(r)=$ $\left[P_{m}(r) \sigma_{m}(r)+P_{a}(r) \sigma_{a}(r)\right] / 4 \pi$, where $P_{m}(r)$ and $P_{a}(r)$ are the molecular and aerosol phase functions at $180^{\circ}$ scattering angle (at range $r$ ), and $\sigma_{m}(r)$ and $\sigma_{a}(r)$ are molecular and aerosol scattering coefficients $\left(\mathrm{m}^{-1}\right)$ at range $r$. For the clean marine atmosphere over Hawaii, where sea-salt aerosols typically dominate, aerosol absorption is negligible; therefore, we assume that the extinction coefficient is the sum of the molecular and aerosol scattering coefficients, $\sigma_{e}(r)=\sigma_{m}(r)+\sigma_{a}(r)$, and the aerosol absorption coefficient is omitted. In the remainder of this paper we will only refer to the aerosol scattering coefficient, which is assumed to be equivalent to the aerosol extinction coefficient. In using Eq. (1) to estimate the aerosol scattering coefficient, the uncertainties lie in the lidar calibration $C$ and in the backscattering coefficient, $\beta(r)$. The $\beta(r)$ is unknown because the aerosol phase function $P_{a}(r)$ is a function of aerosol particle size (and composition), which is typically not known.

We have used a constrained forward-stepping (CFS) approach (Porter et al. 2000, 2001) to convert our lidar measurements into aerosol scattering coefficients. This process is carried out by calculating the aerosol scatter at each distance in a forward-stepping manner and integrating the transmission out to each new range. It is well known (Klett 1981; Hughes et al. 1985) that a simple forward-stepping approach such as this one will develop large errors, at larger ranges, if the aerosol phase function or lidar calibration being employed is wrong. This error is caused by the accumulated error in the transmission term in Eq. (1). The CFS approach consists of collecting horizontal lidar measurements in horizontally homogeneous air, then manually adjusting either the aerosol phase function or the lidar calibration factor until the derived aerosol scattering coefficients (derived from the lidar data) are constant with range. Modeling studies show that if the aerosol scattering coefficient values derived from the forward-stepping approach are constant with range, then the derived aerosol scattering coefficients are also correct (Porter et al. 2000, 2001). Furthermore, as mentioned above, errors in the assumed aerosol phase function can be offset by an error in lidar calibration resulting in correct aerosol scattering coefficients (and vice versa). In order to implement this approach for real lidar data, ideally we should have conditions with horizontally homogeneous aerosol. Perfectly homogeneous conditions rarely occur in the atmosphere. On the other hand, over the openocean conditions do often exist where the aerosol scat- tering values vary about a mean value. Field experiments carried out at Bellows Beach have shown that as long as the aerosol scattering values do not vary systematically over the open ocean (past the coastal reef), then the CFS approach gives aerosol scattering coefficient values that agree with nephelometer and sun photometer measurements within the expected error values (Porter et al. 2000). The small-scale changes in the openocean aerosol scattering (which typically have no trend with range) do add error to the process. Our modeling studies (Porter et al. 2000) showed that the accuracy of the derived aerosol scattering coefficients improves when the range of the horizontal lidar measurements increase. For the SEAS experiment, the usable scanning lidar range of our old detector system was $\sim 3 \mathrm{~km}$. Based on Fig. 8 in Porter et al. (2000), this is expected to result in aerosol scattering errors of less than $35 \%$ in the mixed layer for the aerosol scattering coefficient values experienced during the SEAS experiment. If many lidar scans are averaged, then the small-scale variations are smoothed out and the lidar calibration can be improved somewhat. This approach has been applied to lidar data collected during the SEAS experiment and is expected to reduce the error in the lidar calibration from $35 \%$ to $25 \%$. Comparisons between our lidar-derived aerosol scattering coefficients for the mixed layer during the SEAS experiment and those obtained from measured size distributions and by nephelometry are discussed in Clarke et al. (2003) and are within the expected range of uncertainty. Following the SEAS experiment we have been using a custom logarithmic amplifier (Lienert et al. 2002), which increases the range of our scanning lidar to $10 \mathrm{~km}$, allowing more accurate ( $\sim 15 \%$ error) retrievals of the aerosol scattering coefficient.

Above the mixed layer the aerosol size distribution, and therefore the aerosol phase function (which describes the probability of a photon being scattered at a particular angle), is likely to change so that larger errors are expected in the retrieved aerosol scattering coefficients. However, our data and other vertical salt-mass measurements (Woodcock 1953) show that the sea-salt aerosol concentration is expected to be 2-5 times lower there. When clouds affect the lidar measurements the particle phase function may change, and multiple scattering can also become significant. These effects are not modeled here, so it is assumed that the scattering values derived in and past clouds are less reliable.

While the error in the aerosol scattering (for the mixed layer) is expected to be less than $25 \%$, some additional error will occur in heavy spray from waves breaking over the reef. In these dense salt-spray conditions the aerosol size distribution is larger, resulting in a different aerosol phase function. Porter et al. (2000) investigated the aerosol phase function for a wide range of sea-salt size distributions. They found that the lidar aerosol phase function increased and then decreased as the seasalt size distribution increased (up to hurricane-force conditions) but that for a wide range of common con- 
ditions the aerosol phase function ranged from 0.6 to 0.65 . In processing the lidar data in this paper, we have used a value of 0.6 and therefore expect that the error in the aerosol phase function is at most $0.05(8.3 \%)$. For a short distance in dense salt-spray plumes, the use of this incorrect phase function will result in an additional error of at most $8.3 \%$ (or a total of $33 \%$ ). But if the optical depth through dense salt-spray plumes is large, the error in the calculated transmission will accumulate, resulting in larger errors with distance. Most of our vertical scanning lidar data only passes a short distance $(10-20 \mathrm{~m})$ through the low-level spray from breaking waves. One exception occurs when the laser is pointing horizontally over the reef. In this case the pathlength through the heavy spray can be large and error factors up to 2 can occur for measurements beyond the reef at low height (below $20 \mathrm{~m}$ ). This error is occasionally seen in individual lidar scans and cases where only heavy wave spray was sought (see discussion on Fig. 14). This effect is not present in the overall averages discussed below (Fig. 10) because the spray from the outer reef was not continuous.

The CFS approach described above works equally well in deriving aerosol extinction values for absorbing and nonabsorbing aerosols (Porter et al. 2001). Aerosol absorption is typically small in clean marine aerosol conditions, as was the case for the SEAS experiment, even during the case of enhanced accumulation-mode aerosol near the end of the experiment (Masonis et al. 2003; Clarke et al. 2003). Due to the small aerosol absorption during SEAS, the scattering and extinction coefficients are essentially identical for the conditions studied in this paper.

\section{Background meteorological influences}

Large-scale open-ocean processes, such as wind speeds, and atmospheric stability affect background oceanic aerosol extinction conditions. The increase in seasalt concentration with wind speed has been documented by many investigators (Woodcock 1953; Gathman 1983; Porter and Clarke 1997), and models exist that describe this relationship (Zeisse 1999). The vertical distribution of sea-salt aerosol over Hawaii has been measured using filter and kite measurements (Blanchard et al. 1984; Daniels 1989), and it has been shown that on average larger sea-salt aerosol concentrations occur near the surface with a strong gradient in the lowest $30 \mathrm{~m}$. Above 30-m height, much weaker gradients exist with nearly constant concentrations up to cloud base, where the top of the mixed layer often occurs. Above the mixed layer up to the top of the boundary layer (trade wind inversion) the salt aerosol concentrations often decrease significantly depending on the strength of the lid at the top of the mixed layer. Above the trade wind inversion the free troposphere air typically has very low aerosol scattering values, with the exception of episodic Asian dust or pollution events over Hawaii during spring.

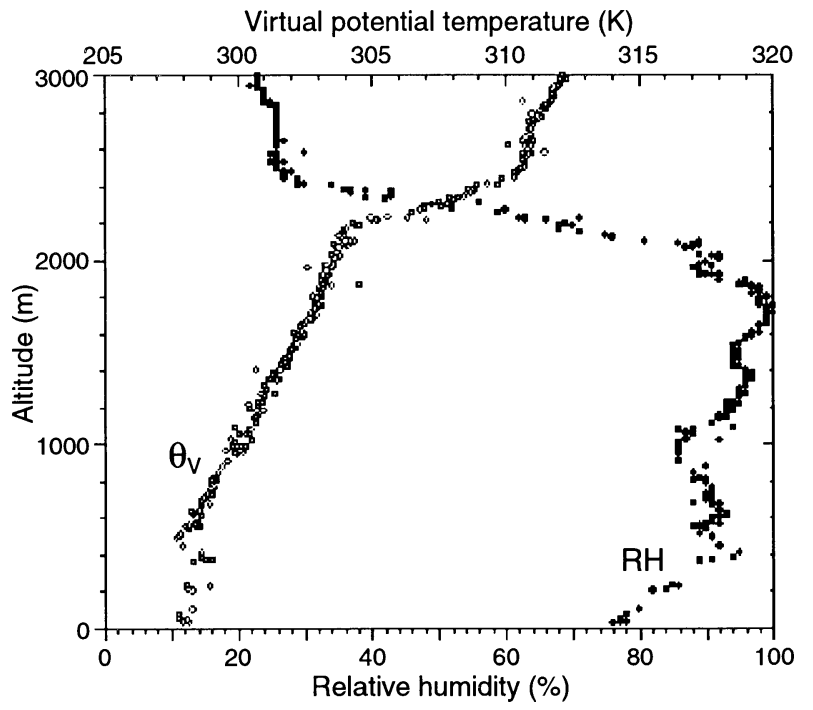

FIG. 3. Vertical distribution of virtual potential temperature and relative humidity measured at Bellows Beach (1600 HST 24 Apr 2000).

To investigate the boundary layer vertical structure during the SEAS campaign, we released a radiosonde to measure the vertical profile of temperature and humidity. The radiosonde was released from a small boat $\sim 2 \mathrm{~km}$ upwind of the lidar site to obtain open-ocean conditions. Figure 3 shows the relative humidity and virtual potential temperature derived from the sounding taken at 1600 HST (Hawaiian standard time) 24 April. The relative humidity is $75 \%$ near the surface and increases with height through the mixed layer, similar to the model proposed by Fitzgerald (1989). The virtual potential temperature is approximately constant in the lowest mixed layer $(0-0.5 \mathrm{~km})$ with a fixed rate of increase from 0.5 to $\sim 2.2 \mathrm{~km}$ and a strong increase from 2.2 to $2.5 \mathrm{~km}$ corresponding to the trade wind inversion. These data indicate that the mixed layer extends from the surface up to $0.5 \mathrm{~km}$ and that the boundary layer is stable above $0.5 \mathrm{~km}$ up to the trade wind inversion $(\sim 2.5$ $\mathrm{km}$ ), where it becomes very stable.

Figure 8 shows the aerosol scattering coefficients obtained from the scanning lidar at the time of the sounding. Note that the sea salt (the cause of the aerosol scattering) is well mixed up to approximately $0.55 \mathrm{~km}$, which is consistent with the mixed layer seen in Fig. 3. Between 0.5 and $2 \mathrm{~km}$ several layered cloud and aerosol fields exist that are consistent with aged trade wind clouds evaporating in a stable stratified layer. The depth of the mixed layer and the strength of the lid (at the top of the mixed layer) affect mixing processes in the boundary layer. If the mixed layer is deeper, then the salt aerosol will be mixed throughout a deeper layer. A clear example of this mixed layer lid effect on salt vertical distributions is shown in Fig. 9, in which the mixed layer is evident up to $\sim 400 \mathrm{~m}$. The height of the mixed layer increases near the island (right-hand side of the image). This island- 


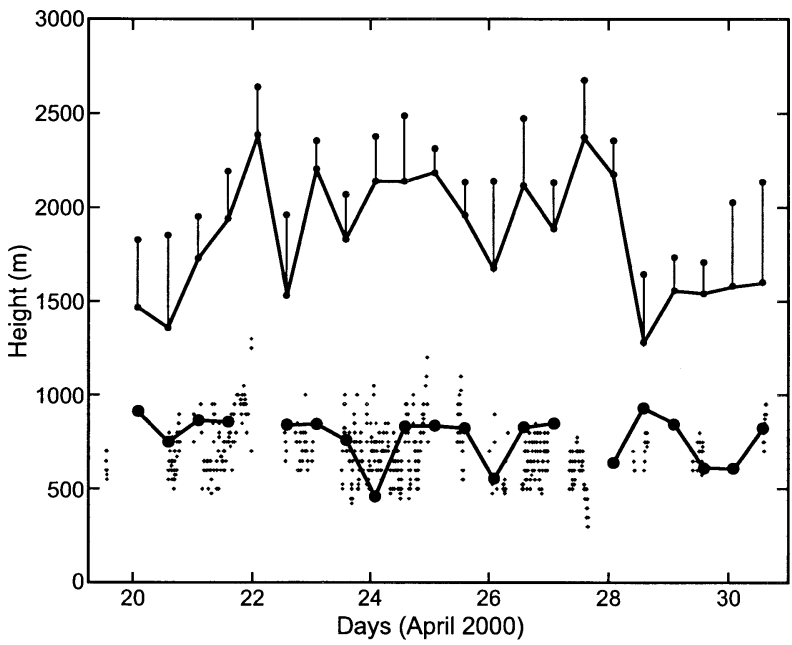

FIG. 4. Time series of height of the mixed layer (heavy dots) and the top and bottom of the trade wind inversion (stars) as observed in the Lihue, Kauai, soundings. Also shown is the mixed layer height inferred from the lidar data at Bellows Beach, Oahu (small dots).

blocking effect is discussed below. Current mesoscale models, such as the fifth-generation Pennsylvania State University-National Center for Atmospheric Research Mesoscale Model (MM5; see http://www.mmm.ucar.edu/ $\mathrm{mm} 5 /$ ), which are initialized from large-scale models, do not capture the trade wind inversion much less the depth and strength of the mixed layer (D. Stevens 2002, personal communication). Layer models (Albrecht 1984) introduce a mixed layer and show its evolution but require further validation (B. Albrecht 2002, personal communication).

One feature, which is not currently modeled, is the rapid variability in the height (depth) of the mixed layer, which we observed during the experiment. Figure 4 shows how the height of the trade wind inversion and mixed layer varied during the SEAS experiment as observed in the lidar datasets (2-10-min intervals). Here the depth of the mixed layer was determined manually from the lidar data as a sudden decrease in the aerosol extinction coefficient. Cases in which the top of the mixed layer could not be clearly defined (because of clouds or other factors) were omitted. The lidar mixed layer heights ranged from 300 to $1300 \mathrm{~m}$.

In order to provide an independent measure of the mixed layer throughout the SEAS experiment, soundings collected at Lihue, Kauai (by the National Weather Service), were studied. The depth of the mixed layer was defined as the area near the surface where the virtual potential temperature was near constant (Stull 1988). The depth of the mixed layer (derived from the Lihue soundings) is also shown in Fig. 4 with a similar range of variability as observed in the lidar measurements. The variability is not as large, probably because of the limited number of soundings (two per day). Also shown is the height of the trade wind inversion (base and top), which was derived from the soundings and shows that

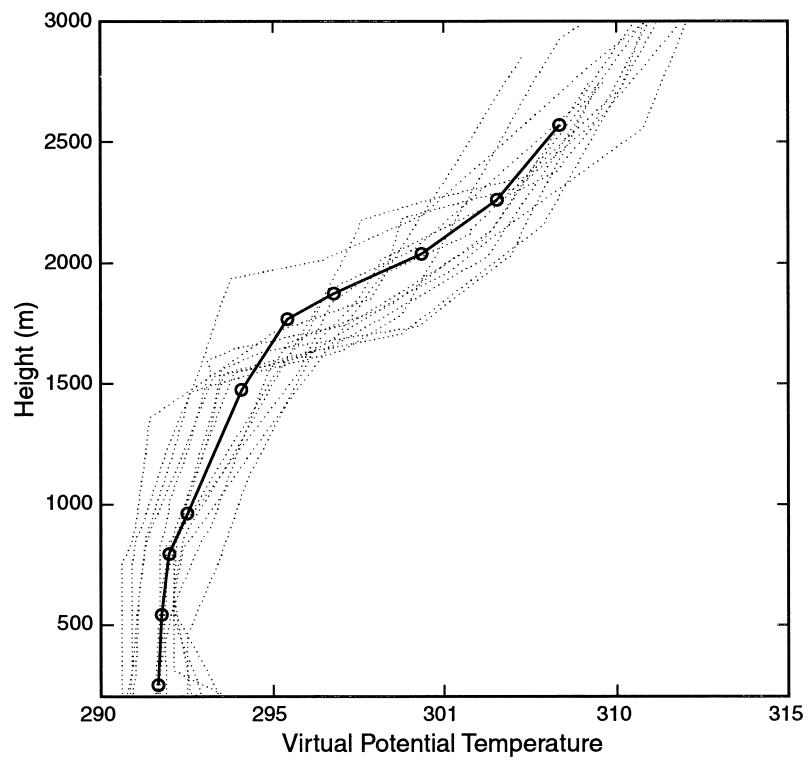

FIG. 5. Feature preserving average of virtual potential temperature at Lihue, Kauai. Only cloud-free soundings were used.

the trade wind inversion top varied from 1.4 to $2.7 \mathrm{~km}$ during the 10-day SEAS experiment. Although the cause of the mixed layer is often attributed to cloud detrainment (cloud-edge evaporative downdrafts and drizzle-induced downdrafts) (Albrecht 1984), this process remains poorly quantified and modeled.

In order to obtain a typical virtual potential temperature profile for the SEAS time period, an average of the Lihue soundings was carried out using a "featurepreserving" average (Atkinson 1971). Only soundings that were not contaminated by clouds were used. The feature-preserving average (Fig. 5) shows the height of the mixed layer at about $800 \mathrm{~m}$, and the trade wind inversion is at about $1800 \mathrm{~m}$ during the SEAS experiment. Substantial variability in the low-level stability (both dry adiabatic and moist adiabatic processes) existed in this short period, which means that on some occasions the low-level thermals were capped at the mixed layer, whereas in other more convective periods the vertical motions should be able to penetrate past the mixed layer and produce trade wind clouds.

\section{Aerosol statistical scattering properties}

Various statistical properties of the aerosol scatter were calculated from the scanning lidar data. Box sizes of $25 \mathrm{~m}$ high by $25 \mathrm{~m}$ long were used as a compromise between good spatial resolution and reasonable lidar counting statistics. Figure $6 a$ shows the frequency distribution of aerosol scattering coefficients in one such box, 75-100 m high and 1600-1625 $\mathrm{m}$ from the shore. This is sufficiently high that spray from breaking waves does not affect it, and it is therefore representative of background trade wind aerosol scattering properties. From Fig. 6a note that a lognormal distribution fits the 
(a)
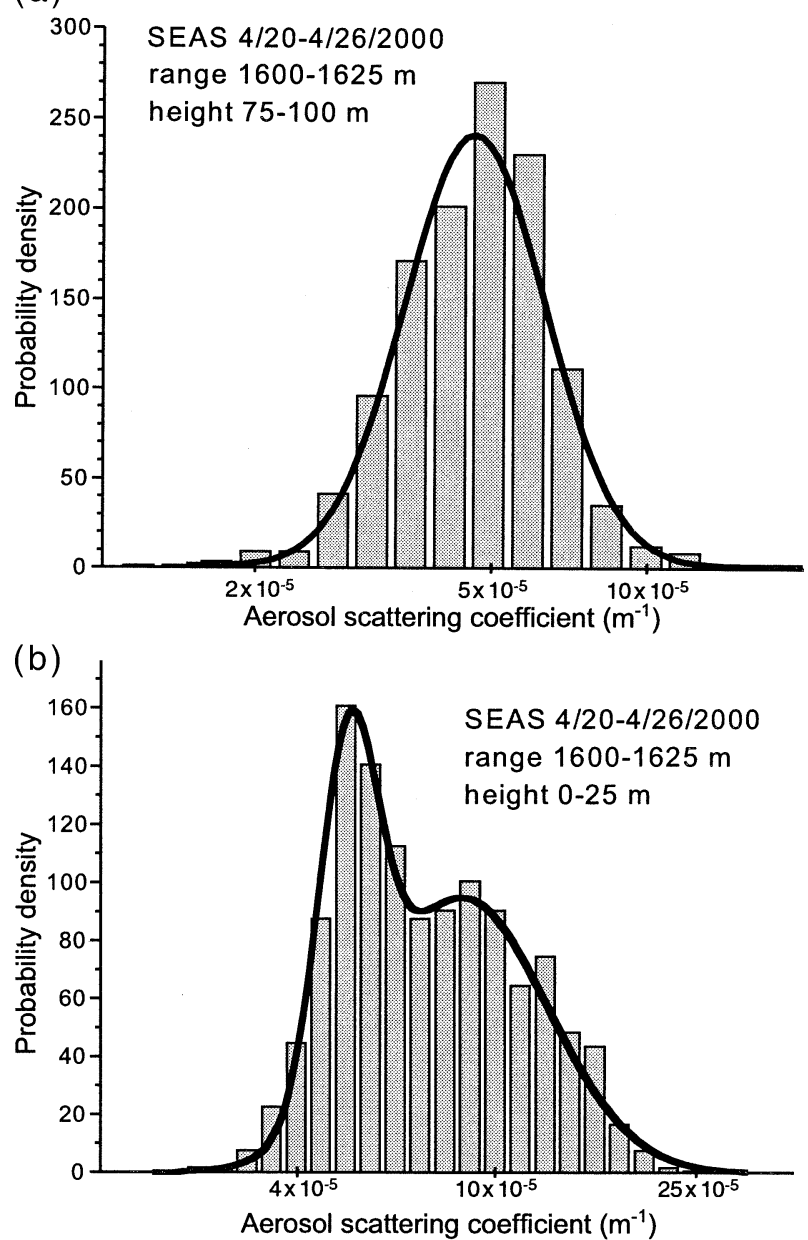

FIG. 6. (a) Frequency distribution of aerosol scattering coefficient occuring (a) at 75-100-m altitude and at 1600-1625-m range and (b) near the surface $(0-25 \mathrm{~m}$ altitude) and at $1600-1625$-m range (near the breaking waves over the reef). Both calculations include all the lidar data collected during the SEAS experiment.

aerosol scattering distribution reasonably well, as was also found by Gerber (1984). Figure $6 \mathrm{~b}$ shows a similar set of values for a box located near the surface just downwind from the breaking waves on the reef. Its bimodal nature is clearly evident, as the sources of aerosol are both the background and the breaking waves. Hooper and Martin (1999) found a somewhat similar bimodal statistical behavior from breaking waves off Wallops Island, Virginia, with the exception that for their measurements the winds were blowing offshore as opposed to the onshore conditions experienced at Bellows Beach.

Figure 7 shows the vertical distribution of average aerosol scattering coefficient (for 1 day) over the reef $(1.8-1.85 \mathrm{~km}$ from the shore). Here we have calculated the average of the logarithm of the aerosol scattering coefficient for each box and then plotted the resulting aerosol scattering coefficient. This is equivalent to the geometric mean of the scattering and has the property
Daily means $4 / 22 / 2000$, range $=1.8-1.85 \mathrm{~km}$

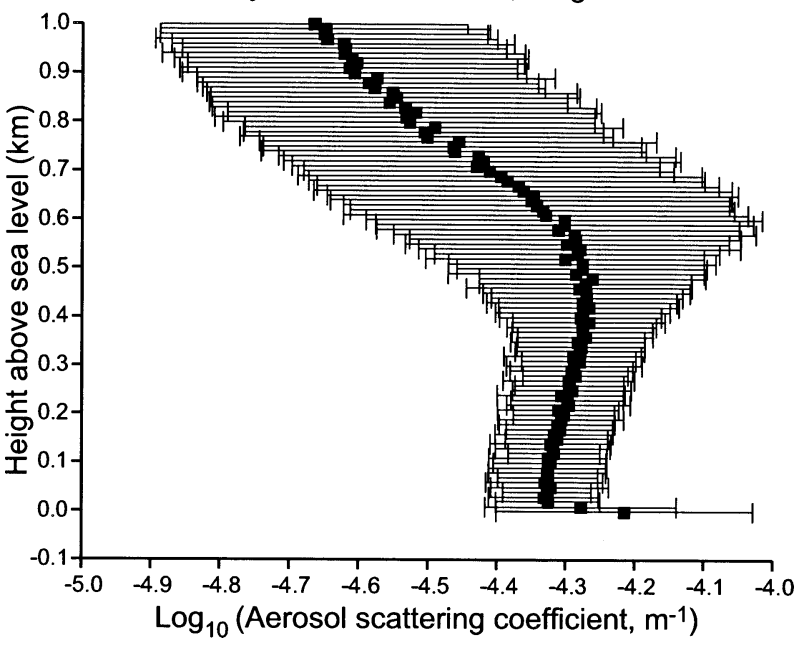

FIG. 7. Vertical distribution of average aerosol scattering coefficients (std dev bars are also shown) derived from the scanning lidar.

that it minimizes the effect of occasional large values, resulting in a value that is somewhat smaller than an arithmetic mean. The lognormal standard deviations are shown as error bars at each height. The aerosol scattering coefficient is roughly constant up to $600 \mathrm{~m}$ then decreases above the mixed layer (similar to the case shown in Figs. 8 and 9).

\section{Island-blocking effects}

When the trade winds encounter the island of Oahu, the mountains have an island-blocking effect, which causes the trade wind to slow just upwind of the island with rising motion and cloud development upwind of the island. At Bellows Beach the mountains are 3-4

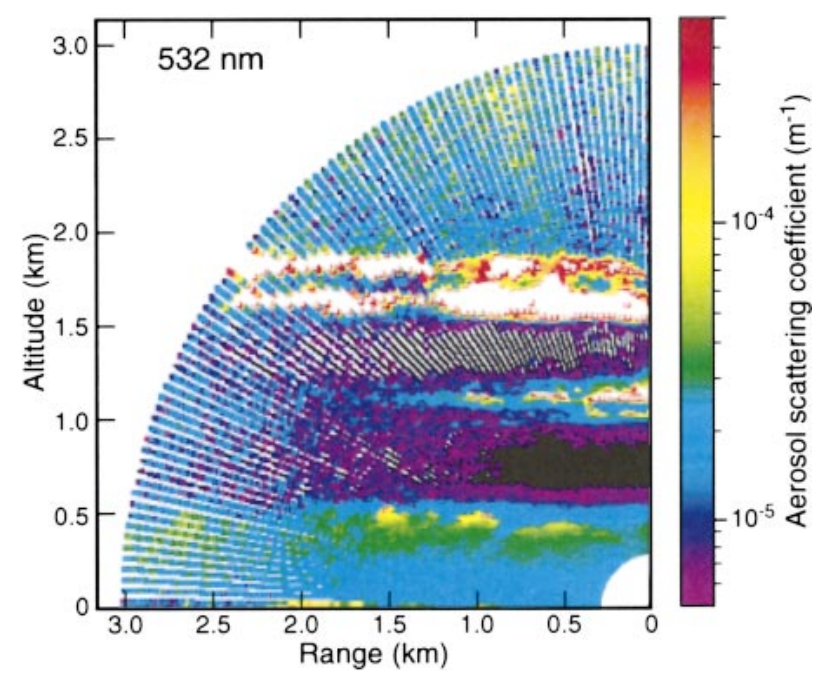

FIG. 8. Vertical distribution of aerosol scattering coefficients derived from the scanning lidar at the same time as the sounding data in Fig. 3. 


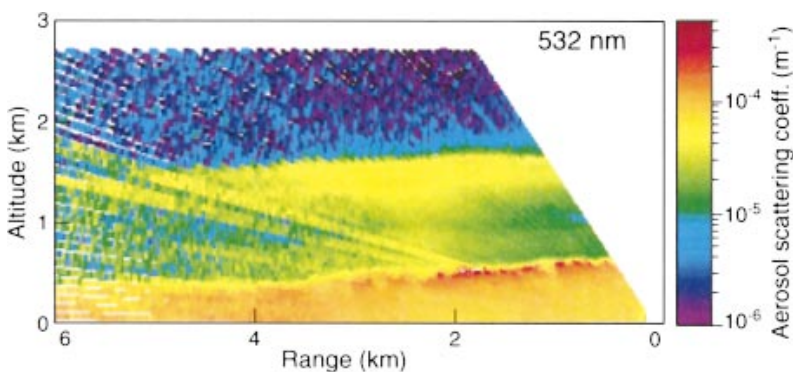

FIG. 9. An example of the aerosol scattering coefficient derived from the scanning lidar. In this case, island blocking is causing an increase in the mixed layer near the island.

miles away from the beach (depending on the direction) and the mountains are $\sim 1000 \mathrm{~m}$ high. Calculations of the Froude number suggest that values were near 0.4 during the SEAS time period, which corresponds to the onset of island blocking (Stull 1988). Here the islandblocking effect is enhanced by the fact that the Koolau mountain ridge $(\sim 1 \mathrm{~km}$ high) is perpendicular to the trade winds direction. An example of the island-blocking effect is shown in Fig. 9, which shows the depth of the mixed layer increasing near the shore and enhanced aerosol scattering near the shore at cloud-base height. We have observed that the sloped nature of the mixed layer appearing in Fig. 9 does not occur often $(\sim 15 \%$ of the time), but when it does it tends to persist for hours. Island-blocking effects are also observed visually at Bellows Beach, as clouds form and grow as they near the island.

Figure 10a shows the spatial distribution of the lognormal average aerosol scattering coefficients calculated from 4 days of vertical scans. Individual values were calculated for boxes, which were $10 \mathrm{~m}$ high by $25 \mathrm{~m}$ wide. Figure 10b shows the lognormal standard deviation for the same data as shown in Fig. 10a. In interpreting these figures several cautions are required. The scattering values derived in clouds (and on the far side of clouds) are expected to be uncertain due to multiple scattering (which we do not account for) and different particle phase functions. Below cloud base (typically at

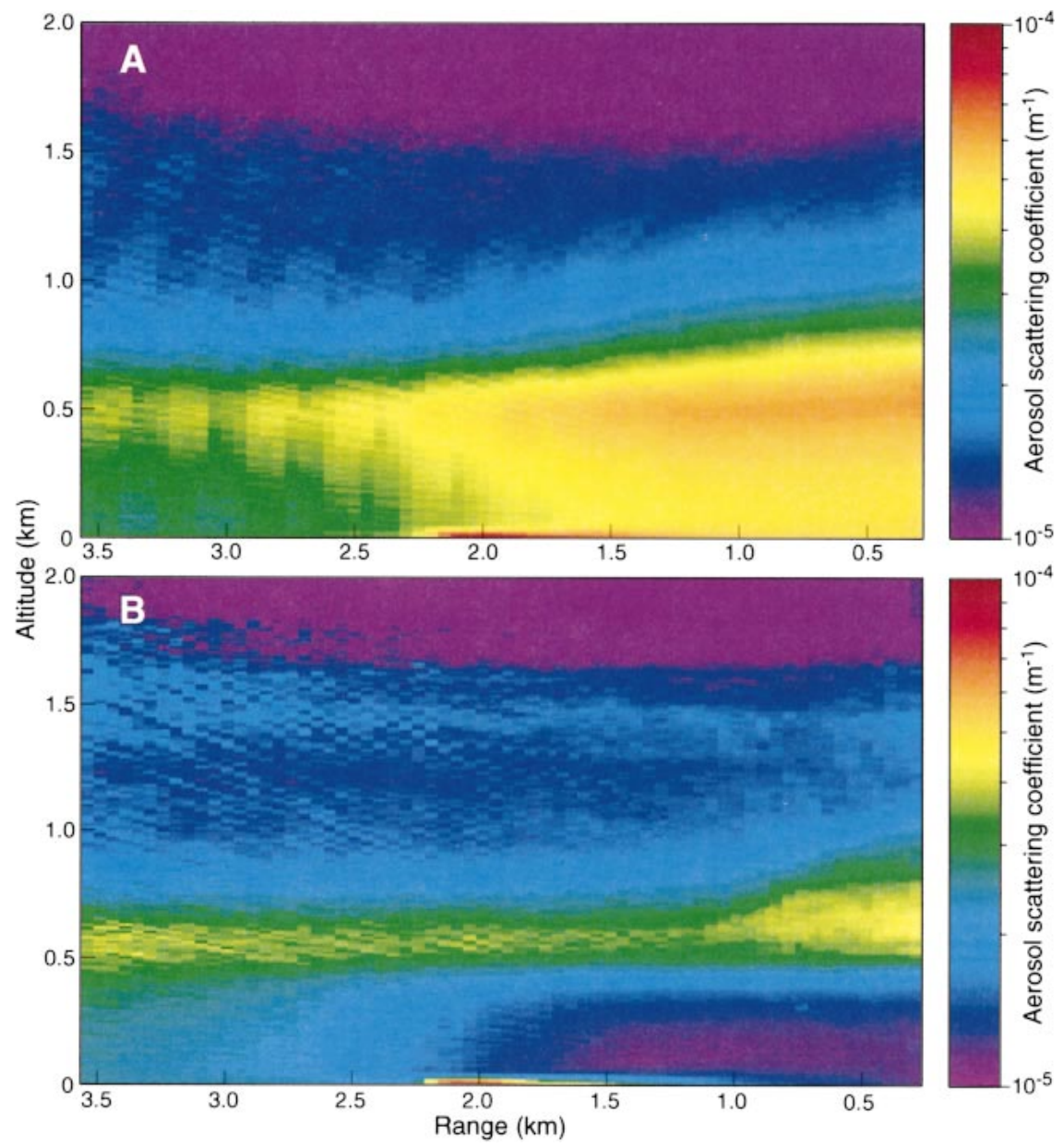

FIG. 10. The spatial distribution of the (a) average and (b) std dev of the log of the aerosol scattering coefficient derived from the scanning lidar data at Bellows Beach. The data for this calculation include all the lidar data collected during the SEAS experiment. 


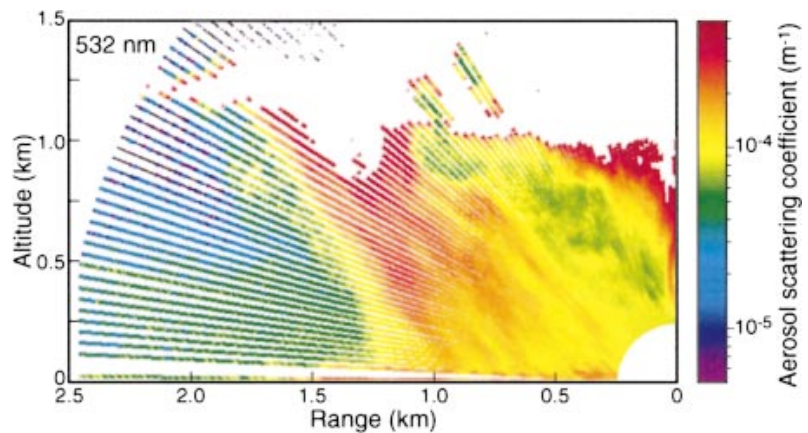

FIG. 11. Vertical scan of lidar measurements during a trade wind shower episode.

$500 \mathrm{~m}$ ) the averages do not suffer from this uncertainty. A separate problem is seen in Fig. 10b at $0-500-\mathrm{m}$ height and at a range of $2.25-3.5 \mathrm{~km}$ from the beach, where the standard deviation increases. This is likely due to degraded signal to noise in our scanning lidar data. The subsequent use of a custom logarithmic amplifier (Lienert et al. 2002) has shown that most of this noise was caused by poor digitization resolution and not from PMT noise. When the signal is small (i.e., at longer ranges), then the digitization error ( \pm 1 count) of our 12-bit digitizer can be a significant fraction of the total counts, which is then amplified by the transmission term [in Eq. (1)]. The standard deviation values in this region (Fig. 10b) are nearly as large as the averages (Fig. 10a). The 4-day average shown in Fig. 10a appears to have removed most this noise, because small box-to-box variations are not evident.

Figures 10a and 10b show that the cloud layer (region of largest standard deviation) was mainly centered near 0.6-km $(0.45-0.75 \mathrm{~km})$ height and that cloud development is occurring near the coastline. During the SEAS experiment the trade winds had an average speed of 7 $\mathrm{m} \mathrm{s}^{-1}$ (Clarke et al. 2003) and never dropped below 5 $\mathrm{m} \mathrm{s}^{-1}$ (for a 30-min average). Therefore, it is unlikely that increased clouds near the coast are due to diurnal land heating effects. Woodcock (Blanchard et al. 1984) analyzed 262 days between 1968 and 1969 and found no significant diurnal change in wind speeds over Oahu during typical trade wind conditions. Island blocking of the trade winds is the more likely reason for enhanced cloud development near the coast. Chen and Feng (2001) have used numerical models to study the wind flow around Hawaii and found both a dynamic windblocking effect as well as a diurnal heating effect on the winds. Similar modeling studies have also been carried out for the island of Oahu (D. Chen 2002, personal communication) showing a significant island-blocking effect with little diurnal heating effect.

\section{Cloud effects on boundary layer scattering fields}

Figure 10a shows an increase in the aerosol scattering coefficient in the mixed layer near the shore. While some

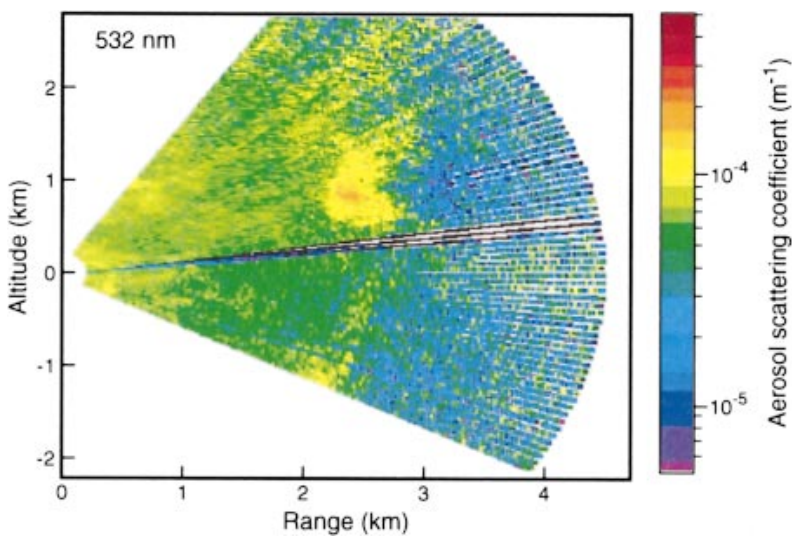

FIG. 12. Lidar scan obtained at 1040 HST 27 Apr 2000 showing a patch of enhanced scatter near the surface due to cloud drizzle.

of this may be attributed to enhanced cloud development near the shore, Fig. 10b shows that the larger standard deviations, which are due to passing clouds, are concentrated between 0.45 - and $0.75-\mathrm{km}$ height and that their mean thickness is increasing near the shore (at ranges of less than $1 \mathrm{~km}$ ). Below $0.45-\mathrm{km}$ height the enhanced scattering seen near the shore in Fig. 10a could be related to two processes, both of which are consistent with the cloud development seen in Fig. 10b near the coastline. As air piles up against the island it can cause a net increase in rising motion, which would cause the air to rise and cool, increasing the relative humidity. The hygroscopic salt aerosols would then swell because of the uptake of water at higher relative humidities. On the other hand, such a process could not explain the observed aerosol scatter increase near the surface (below 100-m height), where the relative humidity would increase little. A second mechanism that might explain the increase in aerosol scattering near the coastline is an increase in drizzle and virga falling from the trade wind clouds as they near the island. Cloud physics models have shown that clean marine conditions, with low cloud condensation nuclei (CCN) concentrations, can be very efficient at producing rain (Takahashi 1976; Porter 1988). Interestingly, A. Woodcock (1989, personal communication) noticed that small trade wind cumulus near Hawaii nearly always had light drizzle directly beneath them, which affected his salt impactor measurements. The drizzle/virga production would also depend on the levels of CCN present (Albrecht 1989). On the basis of these observations, it is likely that an accurate model of coastal optical properties would need to consider cloud drizzle processes as well.

Figure 11 shows a vertical lidar scan with an example of one of the stronger trade wind showers, which occurred during the SEAS experiment. Figure 12 shows a horizontal lidar scan with an example in which drizzle from an isolated trade wind cloud affected the optical scattering properties near the surface. The horizontal lidar scans collected during this period showed numer- 


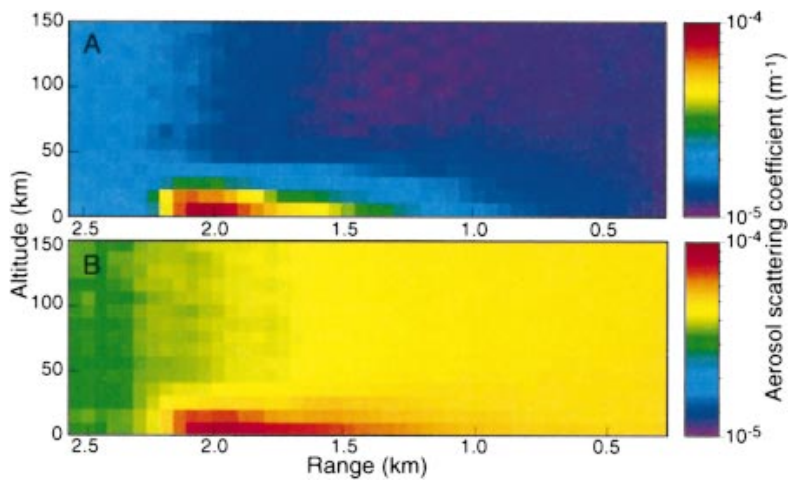

FIG. 13. The lognormal (a) average aerosol scattering coefficient and (b) standard deviation obtained from vertical lidar scans over the reef area.

ous similar patches moving toward shore, which were associated with isolated trade wind showers. The blue areas in Fig. 12 are unusually clean and are possibly due to cloud-related downdrafts bringing aerosol-free air to the surface. Incorporating these small-scale cloud drizzle effects will be a challenge for future modelers.

One interesting feature, which appears in Fig. 11, is the fact that the shower is falling vertically over the lidar while it is tilted out over the ocean. This illustrates the artificial effects introduced by the relatively slow scanning speed $\left(\sim 1^{\circ} \mathrm{s}^{-1}\right)$ of the lidar scanner during the SEAS experiment combined with lateral movement of the rain with the wind. The use of a new logarithmic amplifier is now allowing faster lidar scans to minimize this effect.

\section{Salt spray from breaking waves}

Spray from breaking waves has a large effect on small-scale aerosol variability in coastal regions at low altitude. This is evident in Figs. 10a and 10b near the surface at distances of 1.5-2 km. Figures $13 \mathrm{a}$ and $13 \mathrm{~b}$ show the same data expanded near the surface to illustrate the salt-spray plumes observed over the reef during the SEAS experiment. The salt plumes were confined to below $\sim 40 \mathrm{~m}$ for the typical trade wind conditions experienced during the SEAS experiment $\left(7 \mathrm{~m} \mathrm{~s}^{-1}\right.$ wind speeds). This is consistent with past kite measurements of sea-salt mass at Bellows Beach (Blanchard et al. 1984; Daniels 1989). In Fig. 13a the salt plumes do not reach the beach, possibly because the wind direction varied during the SEAS experiment (Clarke et al. 2003) and the plumes wandered out of the lidar vertical scan. Near the reef the plumes are well captured by the lidar scan.

Breaking waves were not always present on the reef, and approximately $50 \%$ of the time no reef plumes are observed in the scanning lidar data. Movies of the salt plumes show looping properties possibly consistent with random turbulent mixing. During light wind $(\sim 1.8 \mathrm{~m}$ $\mathrm{s}^{-1}$ ) periods (not during the SEAS experiment) we have observed these spray plumes develop very large salt concentrations over the reef area, and they can rise higher (up to $400 \mathrm{~m}$ ) due to reduced wind dilution effect (Sharma et al. 2001). Similar wind dilution effects have been reported at higher wind speeds when observed by nephelometers along the Bellows Beach coastline (see Clarke et al. 2003).

On 27 April 2000 numerous horizontal lidar scans were carried out. Figure 14 shows the locations of the salt plumes in relation to the reef measured on this day. A single scan is shown in Fig. 14a, and the average and standard deviation calculations are shown in Figs. 14b and $14 \mathrm{c}$, respectively. For these statistical calculations only lidar scans that had salt plumes were used, so the standard deviations are only representative of those limited conditions. It can be seen that on average the salt plumes passed just slightly south of the lidar site on this day, and the location of the breaking waves was on a reef farther in.

\section{Sea-salt fluxes}

In order to estimate the fluxes of salt mass from the breaking waves, we must first convert our derived aerosol scattering coefficient values into salt mass concentrations. This requires an estimate of the mass scattering coefficient for sea-salt aerosols. On the basis of the Woodcock (1953) measurements, Porter and Clarke (1997) give a range of salt size distributions for different wind speeds up to hurricane-force winds. As expected, the size distributions tend to shift to larger sizes with increasing wind speed. Using Mie theory calculations and the sea-salt models presented in Porter and Clarke (1997) results in aerosol mass scattering efficiencies (at $75 \%$ relative humidity) of $5,3,1.5,1.3,0.6$, and 0.27 $\mathrm{m}^{2} \mathrm{~g}^{-1}$ for sea-salt mass concentrations of $0.69,3.13$, $12.96,26.5,136$, and $711 \mu \mathrm{g} \mathrm{m} \mathrm{m}^{-3}$. Here the salt hygroscopic uptake of water was modeled following Tang et al. (1997).

As a relative test of our ability to convert the lidarderived aerosol scattering coefficients into sea-salt aerosol mass concentrations, we now compare our derived values with those reported by Blanchard et al. (1984). During the SEAS experiment the average background aerosol scattering coefficient derived from the lidar was $\sim 4.7 \times 10^{-5} \mathrm{~m}^{-1}$ (see Fig. 10a). Under typical clean marine conditions near Hawaii, sea salt contributes $\sim 80 \%$ of the scatter in the mixed layer (Porter 1993), so the salt contribution to the total aerosol scatter is expected to be $\sim 3.8 \times 10^{-5} \mathrm{~m}^{-1}$. Next we divide by an aerosol mass scattering efficiency of $1.5 \mathrm{~m}^{2} \mathrm{~g}^{-1}$, which is based on the sea-salt aerosol model presented in Porter and Clarke (1997) for a wind speed of $7 \mathrm{~m}$ $\mathrm{s}^{-1}$ and a relative humidity of $75 \%$. This results in an aerosol mass concentration of $25 \mu \mathrm{g} \mathrm{m}^{-3}$ for the background salt concentrations. At Bellows Beach, Blanchard et al. (1984) measured an average salt mass concentration of $22 \mu \mathrm{g} \mathrm{m}^{-3}$ at a height of $19 \mathrm{~m}$ on the 


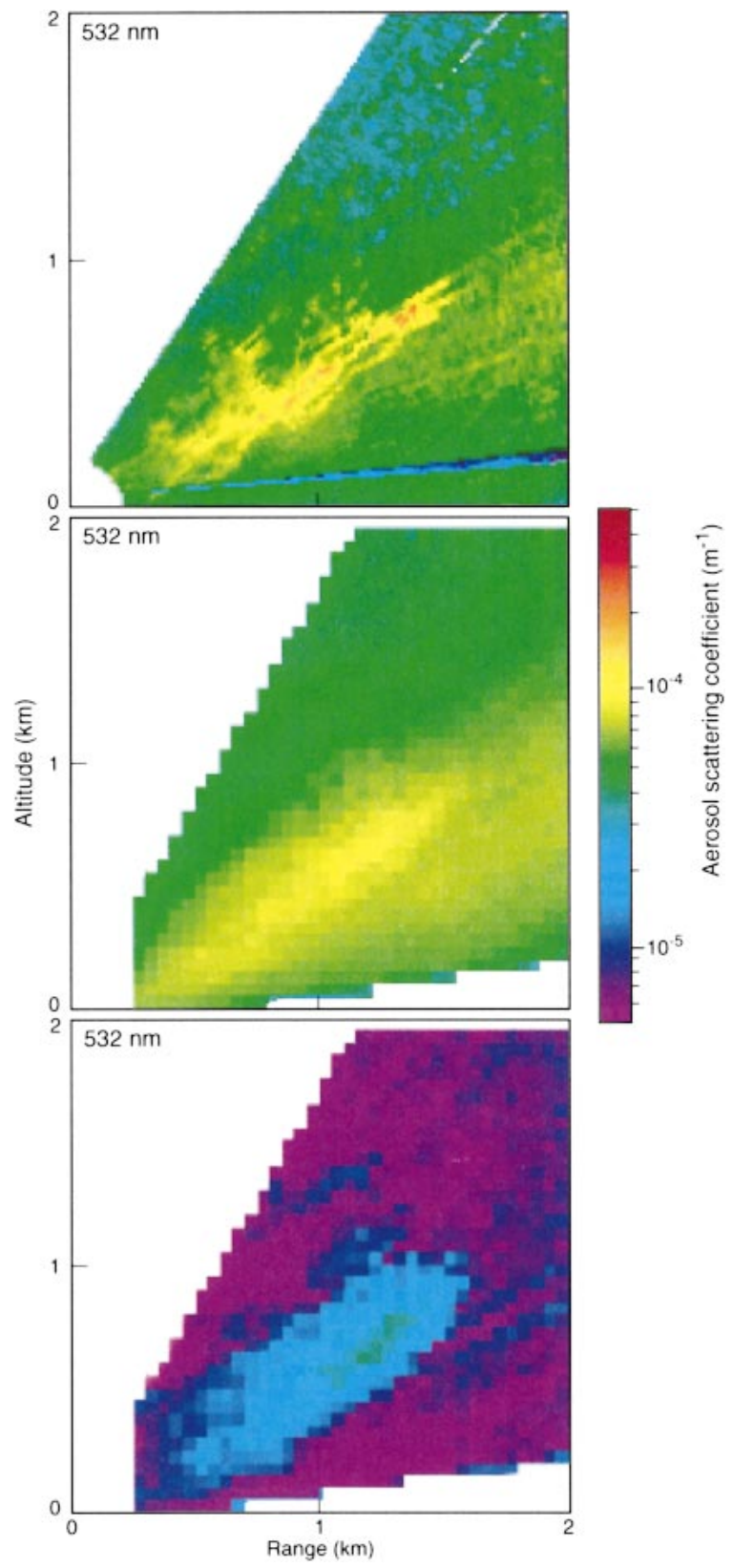

FIG. 14. The aerosol scattering coefficients obtained on 27 Apr 2000 from (a) an individual lidar horizontal scan, (b) an average of many horizontal scans, and (c) the std dev calculated from the lidar scans. Salt spray from the outer reef is seen moving toward the shore.

beach tower, which is slightly lower than our estimated value but within the expected range of uncertainty.

In order to estimate the salt mass flux from the waves breaking on the reef, we assume a larger aerosol size distribution (compared to the background sea-salt size distribution at $7 \mathrm{~m} \mathrm{~s}^{-1}$ ) with a peak in the wet area size distribution near 7- $\mu \mathrm{m}$ diameter (Clarke et al. 2003; Shifrin and Zolotov 2003). This is similar to the size distributions reported in Porter and Clarke (1997) for wind speeds of $14-17 \mathrm{~m} \mathrm{~s}^{-1}$. Based on that size dis- tribution; the sea-salt mass scattering for spray from breaking waves was calculated to be $1.3 \mathrm{~m}^{2} \mathrm{~g}^{-1}$ at $75 \%$ relative humidity. In order to estimate the aerosol scattering coefficient from the sea spray we take the average of the near-surface (0-10- and 10-20-m height) aerosol scatter seen in Fig. $7\left(5.6 \mathrm{~m}^{-1}\right)$ and subtract the background values $\left(4.7 \mathrm{~m}^{-1}\right)$ to obtain a value of $0.9 \mathrm{~m}^{-1}$, which is maintained by the breaking waves. Dividing by the assumed aerosol mass scattering efficiency for spray from breaking waves $\left(1.3 \mathrm{~m}^{2} \mathrm{~g}^{-1}\right.$ at $75 \%$ relative humidity) results in an average salt concentration of 9.0 $\mu \mathrm{g} \mathrm{m}^{-3}$, which is maintained by reef spray. Multiplying by the average wind speed during SEAS $\left(7 \mathrm{~m} \mathrm{~s}^{-1}\right)$ we obtain a salt flux rate of $63 \mu \mathrm{g} \mathrm{m}^{-2} \mathrm{~s}^{-1}$ from waves breaking on the outer reef. Although wind and wave conditions vary at each site, it is useful to compare these salt flux rates with those obtained at other sites. Petelski and Chomka (1996) reported salt mass flux rates from 3.2 to $384 \mu \mathrm{g} \mathrm{m}^{-2} \mathrm{~s}^{-1}$ for heights between 2 and $5 \mathrm{~m}$ for various offshore and onshore wind conditions in the Baltic Sea. De Leeuw et al. (2000) collected size distribution measurements from the surface up to $20-\mathrm{m}$ height at several California sites. He reported salt fluxes of 562-1034 $\mu \mathrm{g} \mathrm{m}^{-2} \mathrm{~s}^{-1}$ at Scripps Pier (La Jolla, California) in January-February 1996 and values of 297$858 \mu \mathrm{g} \mathrm{m}^{-2} \mathrm{~s}^{-1}$ at Moss Landing, California. De Leeuw et al. (2000) suggested that the reasons Petelski and Chomka (1996) obtained smaller lower limits $(3.2 \mu \mathrm{g}$ $\mathrm{m}^{-2} \mathrm{~s}^{-1}$ ) was that they only estimated fluxes for heights between 2 and $5 \mathrm{~m}$, the water in the Baltic Sea has lower salinity $(\sim 10 \%$ o) than the Pacific Ocean $(\sim 33.5 \%)$, the waves were less frequent or smaller, and the bubble size may be smaller in the Baltic Sea. Our estimated salt flux rates from the outer reef at Bellows Beach were significantly lower than those reported by de Leeuw et al. (2000), probably because of the inconsistent nature of waves on the outer reef (discussed below).

During the SEAS experiment, the lidar data showed that salt spray from waves breaking on the outer reef was episodic, and maybe half of the time there was no spray at all. On the other hand, the waves breaking right on Bellows Beach were smaller but continuous. The waves that break on Bellows Beach shore are quite constant in height (0.5-1-m-high faces) and cover an approximately $35-\mathrm{m}$ length to shore. Our scanning lidar measurements, which are pointed out to sea, cannot see the spray from the waves breaking on the beach because they are too close to the lidar $(\sim 15 \mathrm{~m}$ out from the lidar). On one occasion (not during SEAS) we carried out scanning lidar measurements pointed parallel to the beach, which allowed us to measure the spray from the beach waves. Figure 15 shows the vertical distribution of aerosol scatter measured over the beach on 11 June 1999. The lidar measurements were collected nearly directly over the shore. Aerosol scattering values collected over breaking waves during the Electro-Optical Propagation Assessment in Coastal Environments (EOPACE) experiment off the Scripps Pier are also shown in 


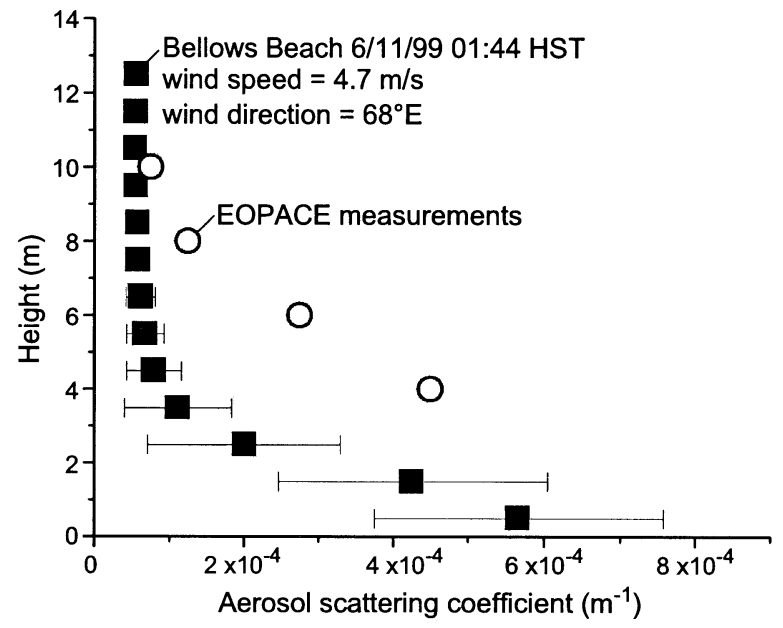

FIG. 15. Vertical distribution of lognormal average and lognormal std dev over the waves breaking on the beach.

Fig. 15 for comparison (Jensen et al. 2001). Even accounting for the large uncertainties in our estimated aerosol scattering values for these measurements ( $\sim 50 \%$ mainly due to poor lidar calibration at that time and uncertainty in the mass scattering efficiency), our Bellows Beach values are significantly lower than those measured at the Scripps Pier (Jensen et al. 2001). This large difference in aerosol concentrations between the two sites is most likely due to lighter winds at the Scripps Pier site (1-3 $\left.\mathrm{m} \mathrm{s}^{-1}\right)$, although wave height and bottom topography also play a role.

In order to obtain the salt flux rate from the waves breaking on Bellows Beach we take the average aerosol scattering coefficient over a height of $0-5 \mathrm{~m}(2.8 \times$ $\left.10^{-4} \mathrm{~m}^{-1}\right)$ and subtract the background value $(7.0 \times$ $10^{-5} \mathrm{~m}^{-1}$ ), which results in an aerosol scattering coefficient of $2.1 \times 10^{-4} \mathrm{~m}^{-1}$ caused by the breaking waves. Dividing this value by an assumed aerosol mass scattering efficiency of $1.3 \mathrm{~m}^{2} \mathrm{~g}^{-1}$ (at $75 \%$ relative humidity) results in a salt mass concentration of $161 \mu \mathrm{g}$ $\mathrm{m}^{-3}$ maintained by the beach spray. Assuming a wind speed of $4.7 \mathrm{~m} \mathrm{~s}^{-1}$ (measured at the time of the beach lidar measurements) results in an average salt mass flux of $760 \mu \mathrm{g} \mathrm{m}^{-2} \mathrm{~s}^{-1}$ from the waves breaking on Bellows Beach shore, which is within the values reported by de Leeuw et al. (2000) (562-1034 $\left.\mu \mathrm{g} \mathrm{m}^{-2} \mathrm{~s}^{-1}\right)$ for breaking waves at the Scripps Pier. Therefore, our estimated salt concentrations over the breaking waves at Bellows Beach were lower than those measured over breaking waves at the Scripps Pier (Jensen et al. 2001), but the salt flux rates were comparable (de Leeuw et al. 2000) between the two sites, which is consistent with the larger winds at Bellows Beach compared to the Scripps Pier.

\section{Discussion}

Based on lidar and sounding data, we found that the top of the mixed layer (often called a transition layer) frequently forms a lid on the large sea-salt concentrations found in the trade wind mixed layer. It was also found that the height of the mixed layer was surprisingly variable (400-800 m) considering the typical trade wind conditions experienced during the SEAS experiment. The maintenance of the mixed layer lid effect requires that cooler air be distributed throughout the mixed layer and warmer air be distributed throughout the cloud layer. One obvious explanation is that latent heat released in clouds warms the cloud layer relative to the mixed layer. But this requires some drizzle or rain to occur since eventual cloud evaporation in the cloud layer would absorb the latent heat released in that layer. Cloud drizzle/virga could also cool the mixed layer through evaporative cooling (Albrecht 1989). A second mechanism is possible. When clouds penetrate (or are in contact with) the dry free troposphere air above the mixed layer they experience strong evaporative cooling, which can result in downdrafts. If these cool downdrafts reach down to below the mixed layer they could cool the mixed layer. Alternatively, if the evaporative cooling is not strong, then the air brought into the cloud layer from these downdrafts may actually warm the cloud layer (the potential temperature in the free troposphere is large), which would also support the maintenance of the mixed layer. Models that explain the presence of a mixed layer have mainly focused on explaining the transition of a stratocumulus-topped boundary layer to a trade wind broken cumulus (Albrecht 1984). Bretherton and Wyant (1997) emphasized the importance of surface latent heat fluxes and cloud-top evaporative cooling in the decoupling of the boundary layer. The backward trajectories (Fig. 2) and wind speeds for the SEAS experiment were fairly constant, so it is expected that the surface fluxes would also be similar and that the mixed layer would also be fairly constant. But our data show that the height of the mixed layer is quite variable (Fig. 4). Two possibilities are that drizzle and cloud detrainment (which affect the mixed layer) are focused in regions with more cloud activity and that small-cloud-scale processes should be a dominant feature in controlling the trade wind structure near Hawaii. We are not aware of other studies that show such large and frequent variability in the mixed layer height. Further studies are needed to better understand and model this variability.

The statistical calculation of the scanning lidar data showed a significant island-blocking effect. As the trade winds approach Oahu, they appear to experience the blocking effect of the mountains ( $\sim 1 \mathrm{~km}$ high) before they reach the shore. Near the coastline it is found that cloud development occurs and is evident in both the average calculations and in the standard deviations. Cloud development appears to begin $2 \mathrm{~km}$ offshore and increase toward the shore. Cloud drizzle and/or enhanced aerosol scatter increases near the shore, affecting the coastline optical conditions.

Modeling the various processes responsible for the coastal optical properties observed during the SEAS ex- 
periment remains a challenge. While mesoscale models have advanced dramatically, to our knowledge none are run at sufficient resolution (below $25 \mathrm{~m}$ ) to resolve individual aerosol sources such as spray from waves breaking on reefs or the shoreline. We have shown that cloud drizzle also plays an important role in coastal optical properties and that island blocking contributes to this effect. Correctly modeling this effect would require knowledge of aerosol concentrations as well as real-time cloud activity. Modeling the small-scale aerosol scatter in the coastal marine boundary layer will also require a statistical approach, as it is difficult to model instantaneously processes that are random or semirandom. One approach to obtain instantaneous estimates of aerosol scatter could be to collect real-time measurements with a small portable scanning lidar and make short-term forecasts. This is the approach the National Weather Service has followed in trying to forecast local rainstorms, which also have semirandom characteristics.

Acknowledgments. The work carried out here was funded by ONR Grant N00014-96-1-0317. We wish to thank Steve Ackleson and Ron Ferek for their support and interest.

\section{REFERENCES}

Albrecht, B. A., 1984: A model study of downstream variations of the thermodynamic structure of trade winds. Tellus, 36A, 187202.

—_ 1989: Aerosol, cloud microphysics and fractional cloudiness. Science, 245, 1227-1230.

Atkinson, G. D., 1971: Forecasters guide to tropical meteorology. Tech. Rep. AWS TR240, Air Weather Service, 249 pp.

Blanchard, D. C., A. H. Woodcock, and R. J. Cipriano, 1984: The vertical distribution of the concentration of sea salt in the marine atmosphere near Hawaii. Tellus, 36B, 118-125.

Bretherton, C. S., and M. C. Wyant, 1997: Moisture transport, lowertropospheric stability, and decoupling of cloud-topped boundary layers. J. Atmos. Sci., 54, 148-167.

Chen, Y. L., and J. Feng, 2001: Numerical simulations of airflow and cloud distribution over the windward side of the island of Hawaii. Part I: The effects of trade wind inversion. Mon. Wea. Rev., 129, $1117-1134$

Clarke, A., and V. Kapustin, 2003: The Shoreline Environment Aerosol Study (SEAS): A context for marine aerosol measurements influenced by a coastal environment and long-range transport. J. Atmos. Oceanic Technol., 20, 1351-1361.

,,-- S. Howell, K. Moore, B. Lienert, S. Masonis, T. Anderson, and D. Covert, 2003: Sea-salt size distributions from breaking waves: Implications for marine aerosol production and optical extinction measurements during SEAS. J. Atmos. Oceanic Technol., 20, 1362-1374.

Daniels, A., 1989: Measurements of atmospheric sea salt concentrations in Hawaii using a Tala kite. Tellus, 41B, 196-206.

de Leeuw, G., F. P. Neele, M. Hill, M. H. Smith, and E. Vignati, 2000: Production of sea spray aerosol in the surf zone. J. Geophys. Res., 105, 29 397-29 409.

Fitzgerald, J. W., 1989: Model of the aerosol extinction profile in a well-mixed marine boundary layer. Appl. Opt., 28, 3534-3538.

Gathman, S. G., 1983: Optical properties of the marine aerosol as predicted by the navy aerosol model. Opt. Eng., 22, 57-62.

Gerber, H. E., 1984: Variability of some optical coefficients of North
Atlantic maritime aerosols. Aerosols and Their Climatic Effects, H. E. Gerber and A. Deepak, Eds., A. Deepak, 63-81.

Hooper, W. P., and L. U. Martin, 1999: Scanning measurement of surf-zone aerosol generation. Opt. Eng., 38, 250-255.

Hughes, H. G., J. A. Ferguson, and D. H. Stephens, 1985: Sensitivity of lidar inversion algorithm to parameters relating atmospheric backscatter and extinction. Appl. Opt., 24, 1609-1613.

Jensen, D. R., S. G. Gathman, C. P. McGrath, C. G. de Leeuw, M. H. Smith, P. A. Fredrickson, and K. L. Davidson, 2001: Electrooptical propagation assessment in coastal environments (EOPACE): Summary and accomplishments. Opt. Eng., 40, 1486-1498.

Klett, J. D., 1981: Stable analytical inversion solution for processing lidar returns. Appl. Opt., 20, 211-220.

Lienert, B. R., J. N. Porter, and S. K. Sharma, 1999: Real time analysis and display of scanning lidar scattering data. Mar. Geod., 22, $259-265$.

,,--- , N. Ahlquist, and D. Harris, 2002: A $50 \mathrm{MHz}$ logarithmic amplifier for use in lidar measurements. J. Atmos. Oceanic Technol., 19, 654-657.

,$- \ldots$, and -2003 : Aerosol size distributions from genetic inversion of polar nephelometer data. J. Atmos. Oceanic Technol., 20, 1403-1410.

Masonis, S. J., T. L. Anderson, D. S. Covert, V. Kapustin, A. D. Clarke, S. Howell, and K. Moore, 2003: A study of the extinction-to-backscatter ratio of marine aerosol during the Shoreline Environment Aerosol Study. J. Atmos. Oceanic Technol., 20, $1388-1402$.

Petelski, T., and M. Chomka, 1996: Marine aerosol fluxes in the coastal zone, BAEX experimental data. Oceanologia, 38, 469484.

Porter, J. N., 1988: Marine aerosol: Their measurement and influence on cloud base properties. M.S. thesis, Dept. of Meteorology, University of Hawaii at Manoa, $67 \mathrm{pp}$.

_ 1993 : Measuring aerosol optical depths from satellite: Aerosol measurements and models. Ph.D. thesis, University of Hawaii at Manoa, $116 \mathrm{pp}$.

__ , and A. Clarke, 1997: An aerosol size distribution model based on in-situ measurements. J. Geophys. Res., 102, 6035-6045.

_ B. B. Lienert, and S. K. Sharma, 2000: Using the horizontal and slant lidar calibration methods to obtain aerosol scattering coefficients from a coastal lidar in Hawaii. J. Atmos. Oceanic Technol., 17, 1445-1454.

_- S. K. Sharma, and B. R. Lienert, 2001: Obtaining calibrated marine aerosol extinction measurements using horizontal lidar measurements, differential lidar-target measurements and a polar nephelometer. SPIE Proc., 1453, 274-281.

Reagan, J. A., 1995: New generation lidars to support aerosol/climateforcing studies. Proc. IGARSS95, Florence, Italy, IEEE, 23132315.

Richter, J. H., and H. G. Hughes, 1991: Marine atmospheric effects on electro-optical system performance. Opt. Eng., 30, 18041820.

Sadler, J. C., M. A. Lander, A. M. Hori, and L. K. Oda, 1987: Tropical Marine Climatic Atlas. University of Hawaii Meteorology Department, Tech. Rep. UHMET 87-02, 27 pp.

Sharma, S. K., B. R. Lienert, J. N. Porter, and A. D. Clarke, 1998: Scanning lidar imaging of marine aerosol fields generated by breaking waves. Proc. 19th Int. Laser Radar Conf., Annapolis, MD, NASA Langley Research Center, 673-676.

$\longrightarrow, \ldots$, and —_, 2001: Scanning lidar measurements of marine aerosol fields at a coastal lidar site in Hawaii. SPIE Proc., 1453, $159-166$.

Shifrin, K. S., and I. G. Zolotov, 2003: The use of direct observations over the aerosol particle size distribution for inverting lidar data. J. Atmos. Oceanic Technol., 20, 1411-1420.

Stull, R. B., 1988: An Introduction to Boundary Layer Meteorology. Kluwer Academic, 666 pp. 
Takahashi, T., 1976: Warm rain, giant nuclei, and chemical balanceA numerical study. J. Atmos. Sci., 33, 269-286.

Tang, I. N., A. C. Tridico, and K. H. Fung, 1997: Thermodynamic and optical properties of sea salt. J. Geophys. Res., 102, 23269 23275 .

Vignati, E., G. de Leeuw, and R. Bercowicz, 2001: Modeling coastal aerosol transport and effects of surf-produced aerosols on pro- cesses in the marine atmospheric boundary layer. J. Geophys. Res., 106, 20 225-20 238.

Woodcock, A. H., 1953: Salt nuclei in marine air as a function of altitude and wind force. J. Meteor., 10, 426-438.

Zeisse, C. R., 1999: NAM6: Batch code for the Navy Aerosol Model. Tech. Rep. 1804, Sparwar Systems Center, San Diego, CA, 63 pp. 
Copyright $\odot 2003$ EBSCO Publishing 